\title{
Estrutura etária da população do Paraná entre 1970 e 2010
}

\section{Population structure age of Paraná state between 1970 and 2010}

\author{
Eduardo de Pintor ${ }^{1}$ \\ Geisiane Michelle da Silva ${ }^{2}$ \\ Ricardo Rippel ${ }^{3}$

\section{RESUMO}

A teoria da transição demográfica teve início com esforço de Frank Notestein (1945) para compreender as mudanças demográficas que estavam ocorrendo no ocidente da Europa desde 0 final do século XIX. A transição demográfica consiste na passagem entre dois cenários de crescimento demográfico, o que altera a estrutura etária da população. O objetivo do artigo é discutir a evolução da estrutura etária paranaense entre 1970 e 2010. As transformações na estrutura etária do Paraná indicam a redução da participação da população jovem e aumento do envelhecimento da população, com crescimento do peso relativo da população idosa. As políticas públicas de educação, saúde, previdência social e mercado de trabalho devem considerar a atual mudança na estrutura etária. Deste modo, o objetivo deste artigo foi analisar a mudança na estrutura etária da população do estado do Paraná. Para isto foram utilizados dados dos Censos Demográficos do Instituto Brasileiro de Geografia e Estatística (IBGE) sobre a distribuição etária da população urbana e rural paranaense e de suas Mesorregiões. Conclui-se que a mudança na estrutura etária ocorre de forma generalizada em todas as Mesorregiões do estado e de maneira desigual entre a população urbana e rural.

Palavras chave: Transição demográfica. Pirâmide etária. Mesorregiões geográficas. Paraná

\section{ABSTRACT}

The theory of demographic transition began with an effort of Frank Notestein (1945) to understand the demographic changes that were occurring in Western Europe since the late nineteenth century. The demographic transition is the transition between two scenarios of population growth, which changes the age structure of the population. The aim of the article is to discuss the evolution of population structure age of Paraná state between 1970 and 2010. The changes in the age structure of the Paraná indicate a reduction in the share of young population and increasing aging population, an increase in the relative weight of the elderly population. Public policies on education, health, social security and labor market should consider the current change in the age structure. Thus, the aim of this study was to analyze the change in the age structure of the population of the state of Paraná. For this we used data

\footnotetext{
${ }^{1}$ Economista da Universidade Federal da Integração Latino-Americana (UNILA). Mestrando do Programa de PósGraduação em Desenvolvimento Regional e Agronegócio da Universidade Estadual do Oeste do Paraná (UNIOESTE/Campus de Toledo) e Economista pela Universidade Estadual de Maringá. E-mail: eduardo.pintor@unila.edu.br.
}

2 Professora Assistente da Universidade Federal da Integração Latino-Americana (UNILA). Mestre em Desenvolvimento Regional e Agronegócio pela Universidade Estadual do Oeste do Paraná (UNIOESTE/Campus de Toledo) e Bacharel em Ciências Econômicas pela Universidade Estadual de Maringá (UEM). E-mail: geisiane.silva@unila.edu.br.

3 Professor adjunto na Universidade Estadual do Oeste do Paraná (UNIOESTE/Campus de Toledo). Doutor em Demografia pela Universidade Estadual de Campinas (UNICAMP), mestre em Desenvolvimento Econômico pela Universidade Federal do Paraná (UFPR) e graduado em Ciências Econômicas pela Universidade Estadual do Oeste do Paraná (UNIOESTE). E-mail: riccardorippel@uol.com.br 
Censuses of the Brazilian Institute of Geography and Statistics (IBGE) on the age distribution of urban and rural Paraná and its Mesoregions. It was concluded that the change in structure occurs group widespread in all Mesoregions state. However, it occurs unevenly between urban and rural population.

Key words: Demographic transition. Age pyramid. Geographic mesoregions. Paraná JEL: J10

\section{INTRODUÇÃO}

As discussões acerca da estrutura etária de uma população e sua relação com o desenvolvimento de uma determinada área, estado, país ou região, permitem verificar que a redução da fecundidade é o fator determinante das transformações. No caso brasileiro, tais transformações passaram a ocorrer a partir da década de 1970, inicialmente nas classes de maior renda e nas regiões mais desenvolvidas do país, posteriormente generalizando-se e desencadeando a transição da estrutura etária da população nacional, que é denominada "transição demográfica".

Segundo Carvalho, Rodriguez e Wong (2008), tal modificação acarreta uma redução da participação da população jovem e aumento da população idosa no montante total da população em foco. De modo que a mudança na estrutura etária da população, consequência da transição demográfica, altera a Razão de Dependência (RD), que corresponde à soma da população de crianças/adolescentes e idosos dividida pela população em idade ativa.

A queda rápida e generalizada da fecundidade, reduz o ritmo de crescimento da população, gerando uma importante mudança estrutural no país, uma vez que a alteração na estrutura etária da população, bem como seu rápido envelhecimento, afeta diretamente a vida econômica e social do Brasil e seus estados, como o Paraná (CARVALHO, 2004).

A compreensão das mudanças na estrutura etária quer ocorre numa determinada população é essencial para a uma aplicação mais eficiente de políticas públicas direcionadas, voltadas para diversos os segmentos específicos da estrutura etária da população. Entre tais políticas podem ser citadas as de educação, saúde, mercado de trabalho e previdência social. Assim, o objetivo deste artigo é o de discutir as alterações na estrutura etária da população do estado do Paraná entre 1970 e 2010, e de suas Mesorregiões Geográficas, entre 1991 e $2010^{4}$, as quais são: Centro Ocidental Paranaense, Centro Oriental Paranaense, Centro-Sul Paranaense, Metropolitana de Curitiba, Noroeste Paranaense, Norte Central Paranaense, Norte Pioneiro Paranaense, Oeste Paranaense, Sudeste Paranaense e Sudoeste Paranaense.

Posto isto observa-se que o artigo está dividido em cinco seções, incluindo a presente introdução. Na segunda seção é realizada uma breve revisão sobre a transição demográfica, Bônus Demográfico e a transição da estrutura etária no Brasil. A terceira seção apresenta a metodologia utilizada neste estudo. A quarta aborda a mudança na estrutura etária na população do estado do Paraná e em suas Mesorregiões. Por fim, as considerações finais encerram o trabalho.

\footnotetext{
${ }^{4}$ Observa-se que esta diferença ocorre em função da disponibilidade de dados disponíveis, que se encontram assim estruturados, e que tem uma origem respalda nas informações provindas do IBGE.
} 


\section{REVISÃO DE LITERATURA}

\section{A transição demográfica}

A teoria da transição demográfica teve início com esforço de Frank Notestein (1945) para compreender as mudanças demográficas que estavam ocorrendo no ocidente da Europa desde o final do século XIX. A transição demográfica refere-se à passagem entre dois cenários de crescimento demográfico (SILVA; MONTE-MÓR, 2010; VIGNA, 2006). A Figura 1 mostra as fases da transição demográfica.

\section{Figura 1 - Esquema teórico da transição demográfica}

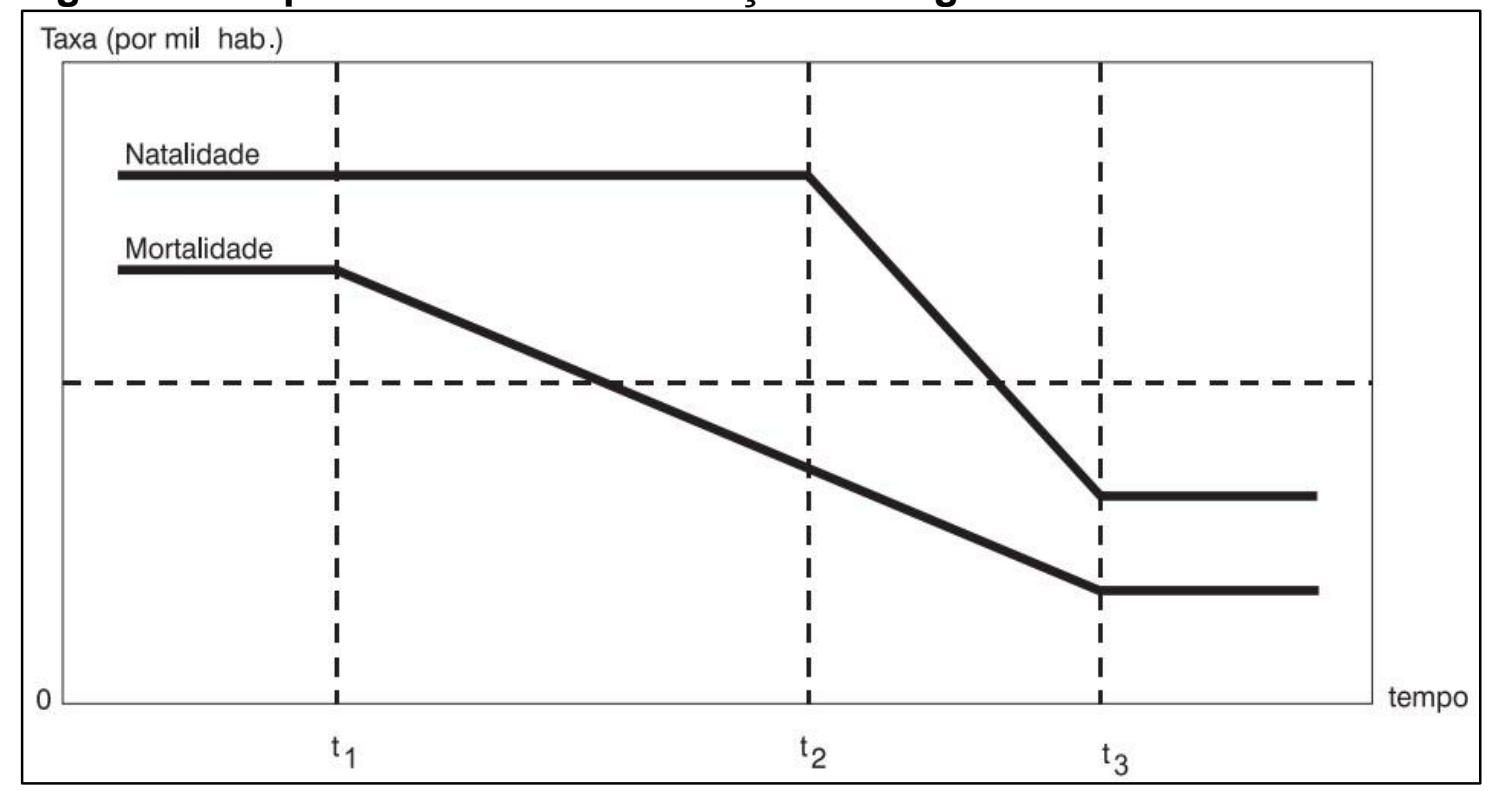

Fonte: Beltrão(1972 apud NADALIN, 2004).

Inicialmente, as taxas elevadas de natalidade e mortalidade fazem com que $o$ crescimento demográfico seja reduzido. Durante a fase de transição, há um crescimento demográfico acelerado decorrente da continuidade de altas taxas de natalidade e da redução da taxa de mortalidade. Por fim, há um baixo crescimento demográfico devido à queda da taxa de natalidade (VIGNA, 2006). De acordo com a Figura 1:

O momento "t1" assinala a passagem do pré-hiato demográfico para a abertura do hiato demográfico; o "t2", a passagem desta fase para o fechamento do hiato demográfico; e o instante " $t 3$ ", finalmente, a passagem para o pós-hiato demográfico (NADALIN, 2004, p.127).

Na primeira fase as taxas brutas de natalidade e mortalidade são elevadas, 0 que faz com que o crescimento vegetativo da população seja baixo. Na segunda fase, inicia-se a queda da mortalidade. Nesta fase, em decorrência da manutenção de altas taxas de fecundidade, eleva-se o crescimento natural da população. $O$ rápido crescimento demográfico da segunda fase desacelera-se com a queda da fecundidade, que caracteriza o início da terceira fase. Com a queda da mortalidade e 
da fecundidade, "[...] o crescimento populacional torna-se muito lento, nulo, ou até negativo" (BRITO et. al., 2007, p. 8), parte deste processo pode ser visualizado na Figura 2 apresentada a seguir.

Figura 2 - Transição Demográfica no Brasil, 1900 - 2050

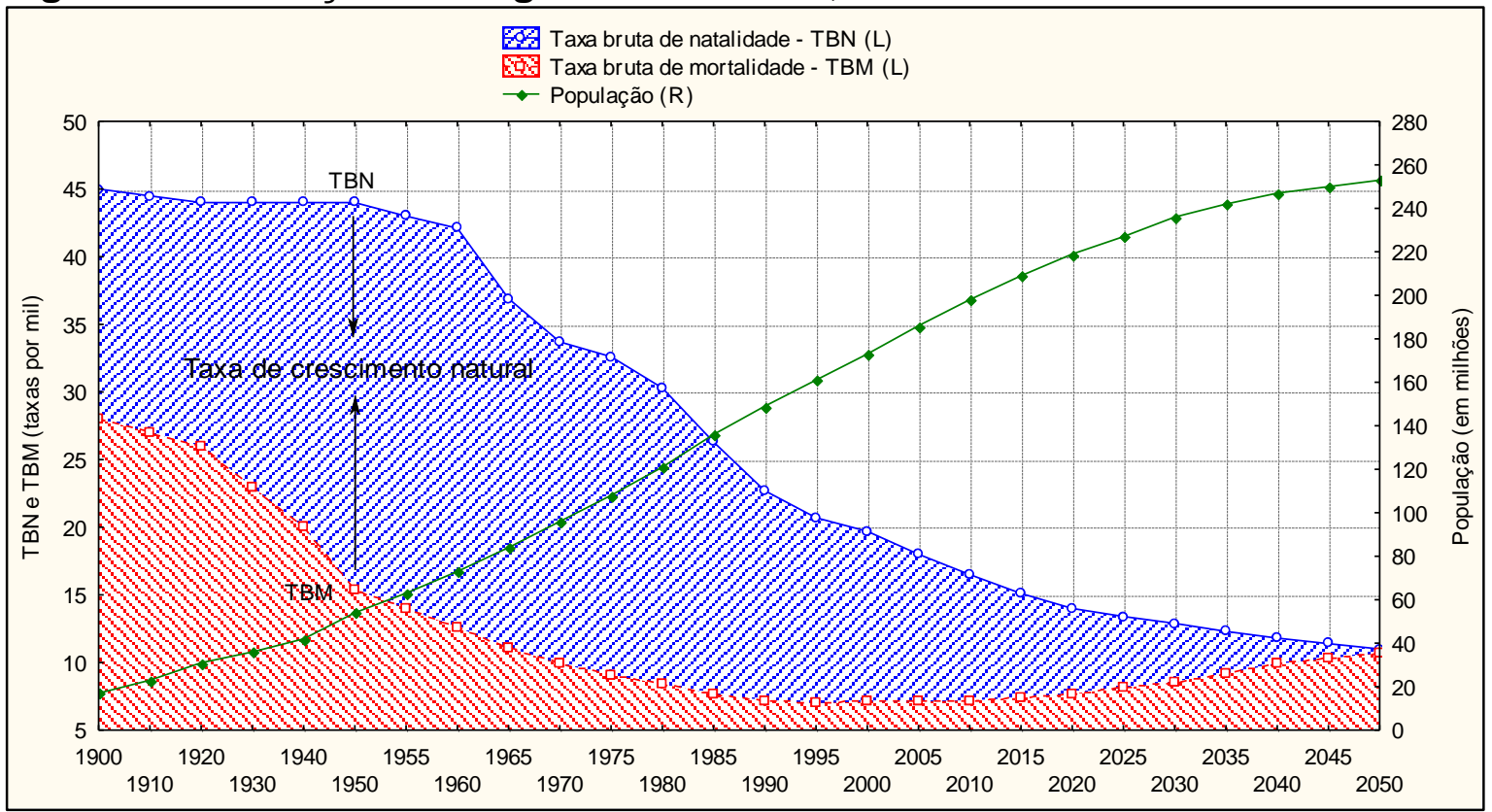

Fonte: ONU (2006 apud ALVES; BRUNO, 2006).

Como se observa a transição demográfica altera a estrutura etária da população. Isto ocorre porque a redução na taxa de fecundidade diminui o tamanho das famílias. Já a redução da taxa de mortalidade contribui para aumentar a esperança de vida e a longevidade. A redução de ambas as taxas dá início ao envelhecimento da população, o qual é caracterizado pela redução da base da pirâmide populacional e o aumento de seu topo (ALVES; CAVENAGHI, 2012).

\section{Bônus demográfico}

Uma das consequências da transição demográfica é a mudança na estrutura etária da população, a qual altera as relações de dependência entre os três principais grupos etários: crianças, adultos e idosos. As crianças (0 a 14 anos) e idosos (acima de 65 anos) são definidos como população "dependente" e a população adulta como População em Idade Ativa (PIA). Deste modo, a Razão de Dependência (RD) demográfica pode ser definida como a soma da população de crianças/adolescentes e idosos dividida pela população em idade ativa (ALVES, 2008). Assim:

O Bônus Demográfico é um fenômeno que ocorre em um período de tempo no qual a estrutura etária da população apresenta menores razões de dependência (menos idosos, crianças e adolescentes) e maiores percentuais de população em idade economicamente ativa, possibilitando que as condições demográficas atuem no sentido de incrementar o crescimento econômico e a melhoria das condições sociais dos cidadãos do país (ALVES, 2010, p. 1). 
O Bônus Demográfico também é chamado de dividendo demográfico ou janela de oportunidades. De acordo com a Divisão de População da Organização das Nações Unidas (ONU), o bônus inicia-se quando o percentual de crianças e adolescentes (0 a 14 anos) fica abaixo de $30 \%$ e termina quando o percentual da população idosa (acima de 65 anos) fica acima de 15\% da população total do país (ALVES, 2010). O processo genérico de surgimento do dividendo pode ser visualizado na figura a seguir.

\section{Figura 3 - Esquema do Dividendo Demográfico}

\section{Declínio da fecundidade}
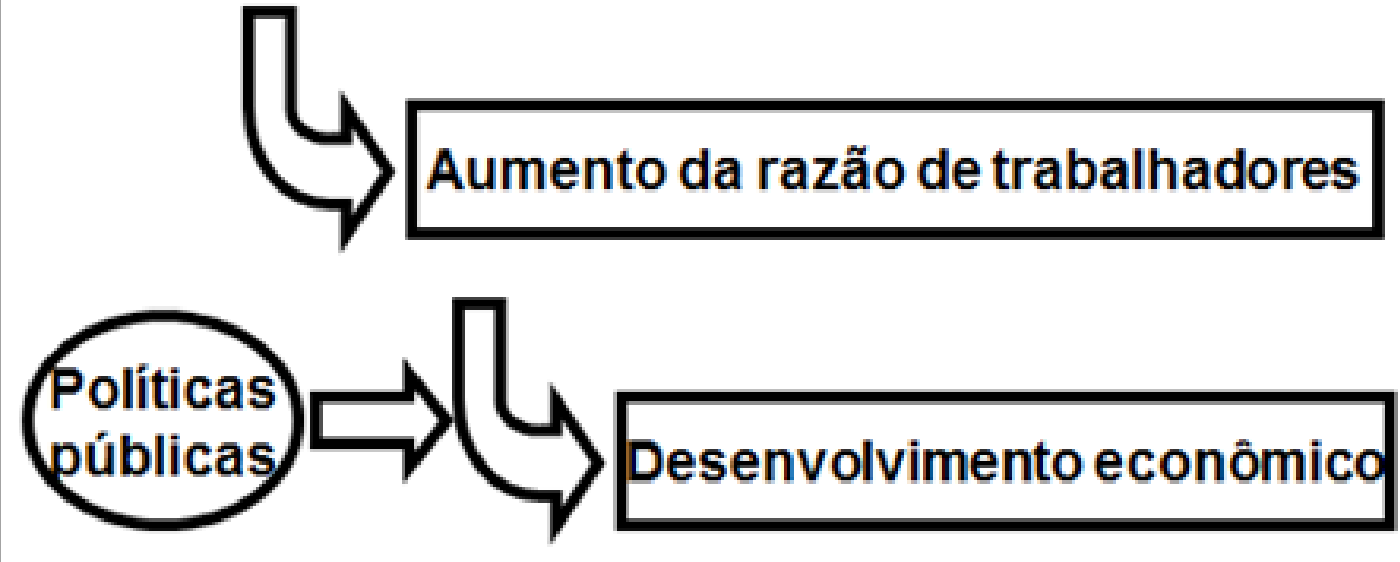

Fonte: Amaral (2008).

Via de regra percebe-se que o bônus consiste no aproveitamento do momento histórico no qual a estrutura etária da população atua no sentido de facilitar o crescimento econômico. Isso acontece quando há um grande contingente da população em idade produtiva e um menor percentual de crianças e idosos no total da população.

É possível verificar que o primeiro Bônus é temporário e refere-se ao crescimento da renda resultante do aumento da razão entre produtores e consumidores na população, decorrente das transições demográfica e da estrutura etária. Outra forma de analisar a duração do bônus é comparar o percentual da PIA com a RD. Assim, o bônus inicia-se quando o percentual da PIA é igual ou maior que o percentual da RD e termina quando o percentual da PIA é igual ou menor que o percentual da RD (ALVES, 2010).

\section{PROCEDIMENTOS METODOLÓGICOS}

Para analisar a mudança na estrutura etária da população do Paraná foram elaboradas pirâmides etárias a partir dos dados dos Censos Demográficos de 1970, 1980, 1991, 2000 e 2010 do Instituto Brasileiro de Geografia e Estatística (IBGE) sobre a distribuição da população residente por sexo e grupos de idade.

A alteração na estrutura etária também foi analisada nas Mesorregiões Geográficas do estado. Para isto foram elaboradas pirâmides etárias a partir dos dados dos Censos Demográficos de 1991, 2000 e 2010 para as Mesorregiões do Paraná, as quais são: Mesorregião Centro Ocidental Paranaense, Mesorregião Centro 
Oriental Paranaense, Mesorregião Centro-Sul Paranaense, Mesorregião Metropolitana de Curitiba, Mesorregião Noroeste Paranaense, Mesorregião Norte Central Paranaense, Mesorregião Norte Pioneiro Paranaense, Mesorregião Oeste Paranaense, Mesorregião Sudeste Paranaense e Mesorregião Sudoeste Paranaense. A Figura 4 traz o mapa das Mesorregiões Geográficas do Paraná.

Figura 4 - Mesorregiões Geográficas do Paraná

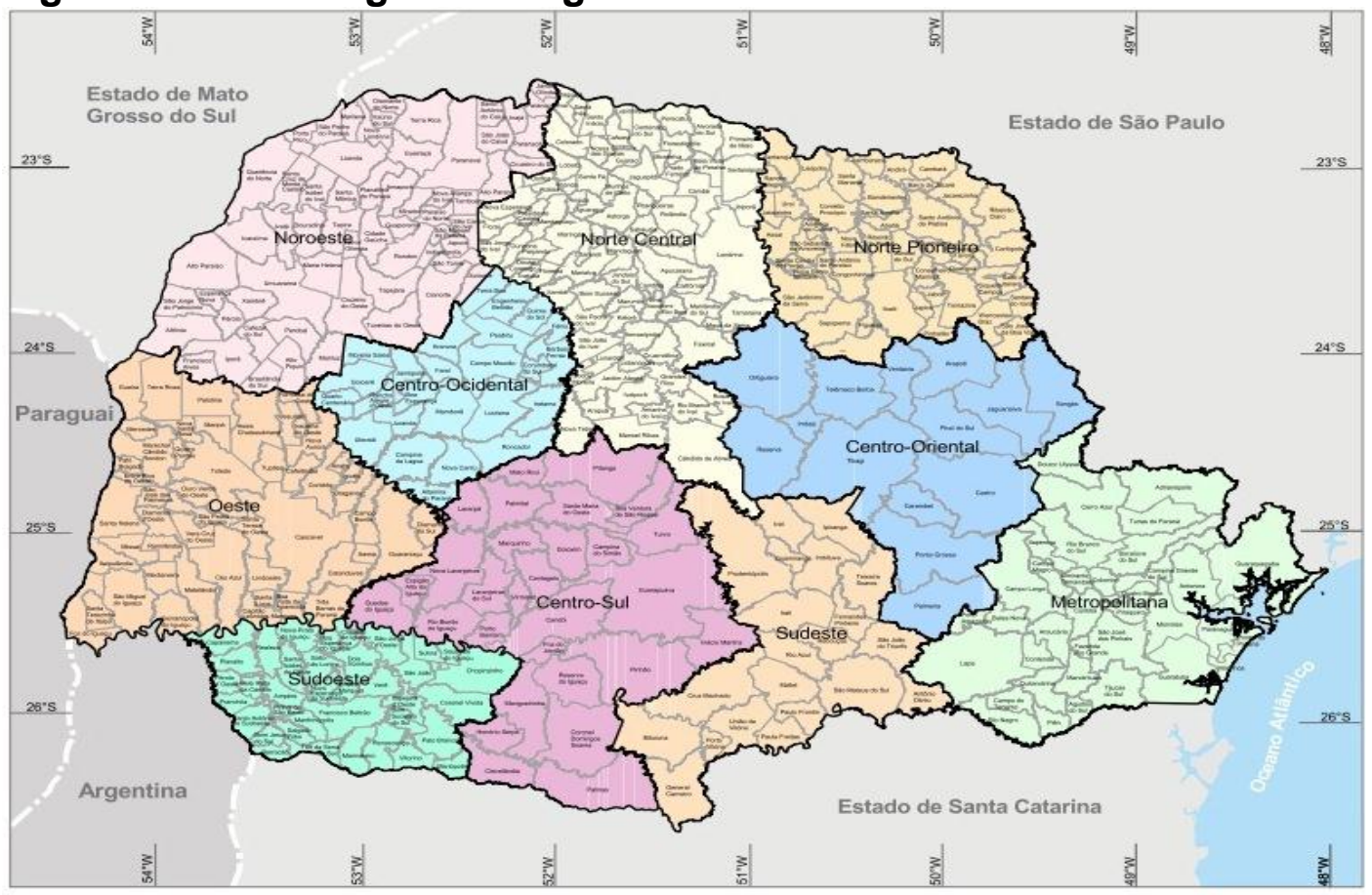

Fonte: IPARDES, 2010.

Para a elaboração das pirâmides etárias, a população do Paraná e de suas Mesorregiões foi dividida de acordo com as seguintes faixas etárias: 0 a 4 anos, 5 a 9 anos, 10 a 14 anos, 15 a 19 anos, 20 a 24 anos, 25 a 29 anos, 30 a 34 anos, 35 a 39 anos, 40 a 44 anos, 45 a 49 anos, 50 a 54 anos, 55 a 59 anos, 60 a 64 anos, 65 a 69 anos, 70 a 74 anos, 75 a 79 anos e 80 anos ou mais.

Além disto, para demonstrar o Bônus Demográfico foi utilizada a Razão de Dependência do Paraná e de suas Mesorregiões do Instituto Paranaense de Desenvolvimento Econômico e Social (IPARDES).

\section{RESULTADOS E DISCUSSÃO}

\section{Transição demográfica e bônus demográfico da população paranaense}

Quando se estuda o comportamento demográfico do Paraná, o que se verifica é que até 1970, a estrutura etária estadual era predominantemente jovem, principalmente em função das elevadas taxas de fecundidade que o Estado, vivenciava e do importante fluxo de imigração notadamente interestadual que esta unidade da federação absorvia (RIPPEL, 2005). Neste cenário vê-se que a queda da participação das crianças e jovens na população estadual, representada pelo estreitamento da base da pirâmide, é segundo o autor consequência da redução da fecundidade paranaense e brasileira no período. 
No período entre 1970 e 2010, a população paranaense entre 0 e 4 anos, 5 e 9 anos e 10 e 14 anos reduziu-se de modo destacado, respectivamente, de 1.167.188 para 713.881; de 1.062.351 para 768.059 e de 915.493 pessoas para 909.399.

Ao mesmo tempo em que isto ocorreu, no outro extremo da pirâmide acontece um movimento inverso, pois a população com faixa etária entre 70 e 74 anos, 75 e 79 anos e acima de 80 anos aumentou de 42.579 para 215.253; de 20.927 para 144.339 e de 21.119 pessoas para 144.342, respectivamente. A Figura 5 mostra as pirâmides etárias do Paraná, entre 1970 e 2010.

Figura 5 - Pirâmides etárias do Paraná nos anos de 1970, 1980, 1991, 2000 e 2010

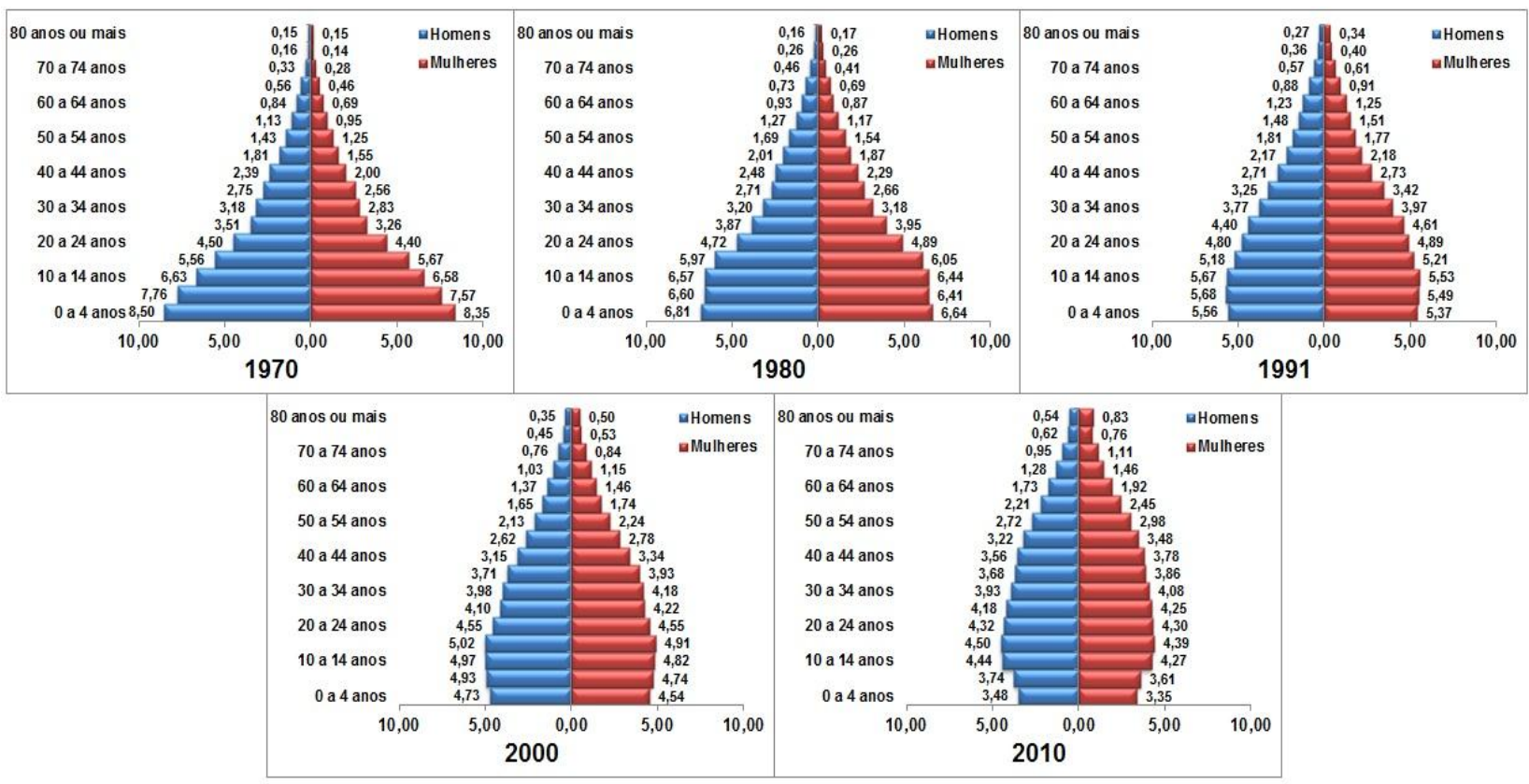

Fonte: IBGE, 2013.

De acordo com a Figura 5, no período analisado houve redução da participação relativa das crianças e aumento da população idosa, o que caracteriza o processo de envelhecimento da população, o qual é consequência da redução da taxa de fecundidade.

Em 1970, a população paranaense apresentava a seguinte estrutura etária: 0 a 4 anos (16,84\% do total), 5 a 9 anos (15,33\%), 10 a 14 anos (13,21\%), 15 a 19 anos (11,23\%), 20 a 24 anos (8,90\%), 25 a 29 anos (6,77\%), 30 a 34 anos (6,01\%), 35 a 39 anos (5,30\%), 40 a 44 anos (4,40\%), 45 a 49 anos (3,36\%), 50 a 54 anos (2,68\%), 55 a 59 anos (2,08\%), 60 a 64 anos (1,53\%), 65 a 69 anos (1,02\%), 70 a 74 anos $(0,61 \%), 75$ a 79 anos $(0,30 \%)$ e 80 anos ou mais $(0,30 \%)$.

E em 2010, passou a apresentar a seguinte composição: 0 a 4 anos $(6,83 \%$ do total), 5 a 9 anos (7,35\%), 10 a 14 anos (8,71\%), 15 a 19 anos (8,89\%), 20 a 24 anos (8,63\%), 25 a 29 anos (8,43\%), 30 a 34 anos (8,01\%), 35 a 39 anos (7,54\%), 40 a 44 anos (7,34\%), 45 a 49 anos (6,71\%), 50 a 54 anos (5,70\%), 55 a 59 anos (4,65\%), 60 a 64 anos (3,65\%), 65 a 69 anos (2,74\%), 70 a 74 anos (2,06\%), 75 a 79 anos $(1,38 \%)$ e 80 anos ou mais (1,38\%). A Tabela 1 demonstra a transição demográfica e o Bônus Demográfico da população paranaense entre 1970 e 2010. 
Tabela 1 - Composição etária da população paranaense nos anos de 1970, 1980, 1991, 2000 e 2010 - (\%)

\begin{tabular}{c|c|c|c}
\hline \hline Período & 0 a 14 anos & 15 a 64 anos & $\begin{array}{c}\text { Acima de 65 } \\
\text { anos }\end{array}$ \\
\hline \hline 1970 & 45,38 & 52,26 & 2,23 \\
1980 & 39,46 & 57,32 & 3,15 \\
1991 & 33,31 & 62,33 & 4,36 \\
2000 & 28,73 & 65,63 & 5,63 \\
2010 & 22,89 & 69,55 & 7,56 \\
\hline \hline
\end{tabular}

Fonte: IBGE, 2013.

De acordo com a Tabela 1, entre 1970 e 2010, a população paranaense apresentou grande redução de crianças e jovens e aumento de idosos. Pode-se verificar que em 1970 os jovens (de 0 a 14 anos) correspondiam a 45,38\% da população (3.145.032 pessoas) e passaram a representar, em 2010, 22,89\% (2.391.339 pessoas). Enquanto a população acima de 65 anos passou de 154.981 pessoas, ou seja, 2,23\%\% da população em 1970, para 790.610 (7,56\%) em 2010.

De modo que a PIA passou de 52,26\% para 69,55\%, entre 1970 e 2010, o que corresponde um aumento de 3.621 .140 pessoas para 7.262 .576 pessoas. A mudança na estrutura etária da população paranaense diminuiu a Razão de Dependência da população do estado, a qual é apresentada no Gráfico 1.

\section{Gráfico 1 - Razão de Dependência da população paranaense entre 1980 e 2010}

(\%)

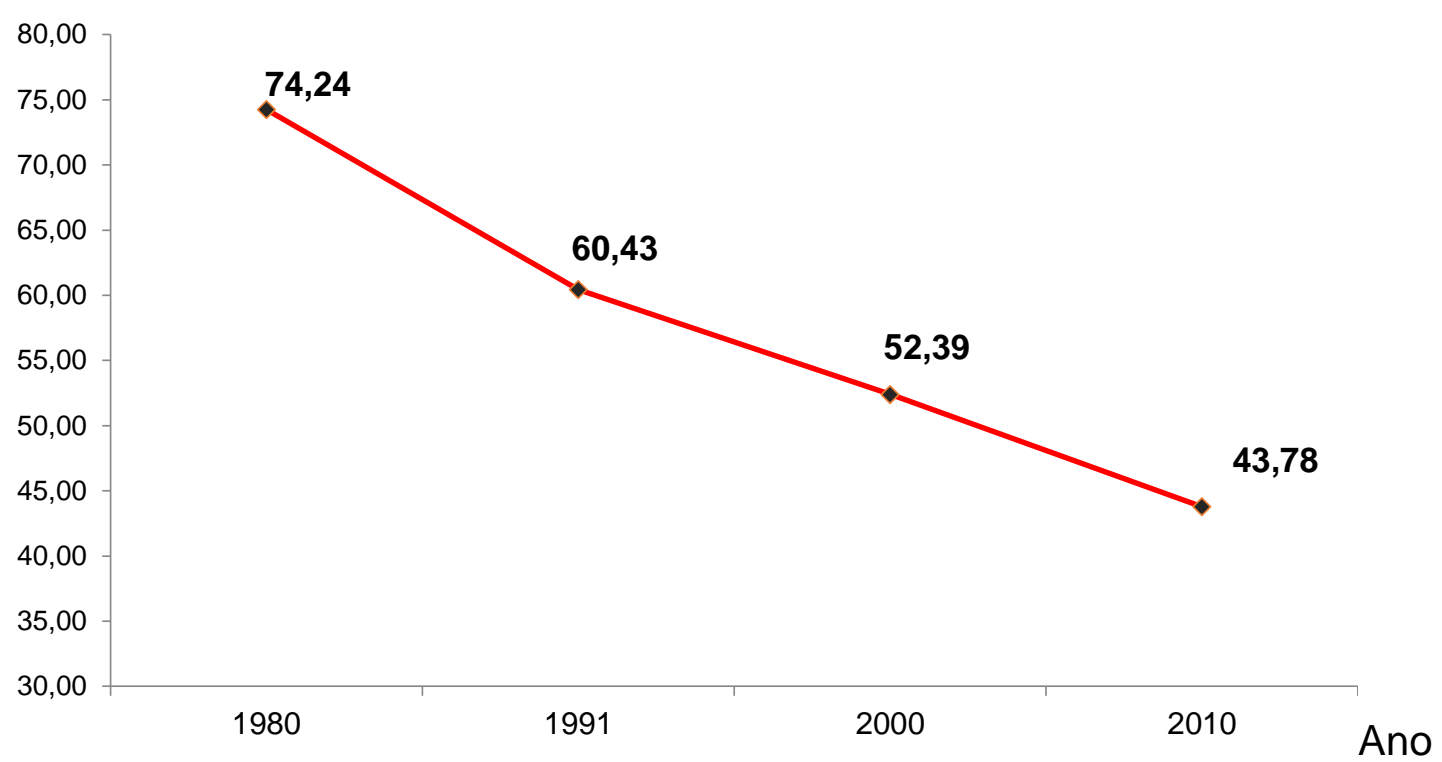

Fonte: IPARDES, 2013.

Em 1980, de acordo com o Gráfico 1, a Razão de Dependência do Paraná era de $74,24 \%$, ou seja, para cada 100 pessoas em idade produtiva existiam quase 75 pessoas "dependentes". Em 2010, a Razão de Dependência reduziu-se para aproximadamente 44 pessoas "dependentes" para cada 100 pessoas em idade ativa. 
Isto é resultado da transição demográfica no estado, que reduziu a participação da população entre 0 e 14 anos e aumentou a participação da população acima de 65 anos.

\section{Transição demográfica e bônus demográfico das mesorregiões paranaenses}

A mudança na estrutura etária da população do Paraná pode ser verificada também nas Mesorregiões do estado. Entre 1991 e 2010, as pirâmides etárias da população do Paraná e de suas Mesorregiões apresentaram comportamento similar. A Tabela 2 mostra a participação das faixas etárias entre 0 e 14 anos, de 15 a 64 anos e acima de 65 anos na população total de cada Mesorregião do Paraná.

De acordo com a Tabela, no período analisado, todas as Mesorregiões ampliaram a participação relativa da população com idade acima de 65 anos, aumentaram a população de 15 a 64 anos e reduziram o peso relativo da população de até 14 anos.

Tabela 2 - Composição etária da população das Mesorregiões paranaenses em 1991 e 2010 - (\%)

\begin{tabular}{l|c|c|c|c|c|c}
\hline \hline \multirow{2}{*}{ Mesorregião } & \multicolumn{2}{|c|}{$\mathbf{0}$ a 14 anos } & \multicolumn{2}{c|}{$\mathbf{1 5}$ a 64 anos } & \multicolumn{2}{c}{$\begin{array}{c}\text { Acima de 65 } \\
\text { anos }\end{array}$} \\
\cline { 2 - 7 } & $\mathbf{1 9 9 1}$ & $\mathbf{2 0 1 0}$ & $\mathbf{1 9 9 1}$ & $\mathbf{2 0 1 0}$ & $\mathbf{1 9 9 1}$ & $\mathbf{2 0 1 0}$ \\
\hline \hline Centro Ocidental Paranaense & 34,24 & 22,26 & 61,57 & 68,65 & 4,19 & 9,09 \\
Centro Oriental Paranaense & 34,74 & 25,88 & 60,70 & 67,31 & 4,55 & 6,81 \\
Centro-Sul Paranaense & 37,73 & 27,32 & 58,80 & 66,20 & 3,40 & 6,46 \\
Metropolitana de Curitiba & 32,27 & 22,91 & 63,57 & 70,63 & 4,15 & 6,47 \\
Noroeste Paranaense & 32,12 & 21,46 & 62,86 & 69,06 & 5,02 & 9,52 \\
Norte Central Paranaense & 31,63 & 20,91 & 63,55 & 70,36 & 4,81 & 8,72 \\
Norte Pioneiro Paranaense & 33,42 & 22,32 & 61,13 & 68,00 & 5,46 & 9,67 \\
Oeste Paranaense & 34,50 & 23,04 & 62,04 & 69,80 & 3,45 & 7,16 \\
Sudeste Paranaense & 34,79 & 25,20 & 60,41 & 67,48 & 4,80 & 7,30 \\
Sudoeste Paranaense & 35,00 & 22,77 & 60,99 & 69,07 & 4,03 & 8,15 \\
\hline \hline
\end{tabular}

Fonte: IBGE, 2013.

Deste modo, o período de 1970 a 2010 foi caracterizado pelo estreitamento da base da pirâmide etária e pelo alargamento de seu topo. Isto caracteriza a redução da taxa de fecundidade e o envelhecimento da população paranaense. A partir das pirâmides etárias de 1991, 2000 e 2010, observa-se que esta mudança na estrutura etária da população paranaense, consequência da redução da natalidade e aumento da longevidade, ocorre em todas as Mesorregiões do estado.

Entre 1991 e 2010, pode-se observar que a PIA aumentou em todas as Mesorregiões do estado a uma taxa média de 7,10\%. Considerando apenas a população em idade ativa a taxa de crescimento média foi de $11,53 \%$ no período. Isso evidencia uma grande expansão da força de trabalho em todo o estado.

A mudança na estrutura etária da população, decorrente da transição demográfica, alterou a Razão de Dependência (RD) das Mesorregiões paranaenses, o que pode ser observado na Tabela 3. 
Tabela 3 - Razão de Dependência das Mesorregiões paranaenses - 1980, 1991, 2000 e 2010 - (\%)

\begin{tabular}{l|c|c|c|c}
\hline \multicolumn{1}{c|}{ Mesorregião } & $\mathbf{1 9 8 0}$ & $\mathbf{1 9 9 1}$ & $\mathbf{2 0 0 0}$ & $\mathbf{2 0 1 0}$ \\
\hline \hline Centro-Ocidental Paranaense & 83,67 & 62,42 & 54,98 & 45,45 \\
Centro-Oriental Paranaense & 73,34 & 64,73 & 56,82 & 48,46 \\
Centro-Sul Paranaense & 86,43 & 69,66 & 62,02 & 50,49 \\
Metropolitana de Curitiba & 64,70 & 57,32 & 49,35 & 41,63 \\
Noroeste Paranaense & 77,85 & 59,09 & 53,13 & 44,74 \\
Norte Central Paranaense & 70,29 & 57,35 & 49,48 & 42,04 \\
Norte Pioneiro Paranaense & 77,28 & 63,59 & 55,37 & 46,84 \\
Oeste Paranaense & 80,02 & 61,17 & 52,96 & 43,16 \\
Sudeste Paranaense & 77,78 & 65,52 & 58,26 & 48,35 \\
Sudoeste Paranaense & 82,03 & 64,94 & 56,78 & 46,06 \\
\hline \hline
\end{tabular}

Fonte: IPARDES, 2013.

De acordo com a Tabela 3, em 1980, as Mesorregiões Metropolitana de Curitiba e Norte Central Paranaense detêm as menores Razões de Dependência do estado para todo o período analisado. Essas Mesorregiões são as únicas que apresentam as RD menores que as RD do estado para todos os anos avaliados. Elas são a primeira e segunda, respectivamente, maiores Mesorregiões do estado em termos de população e PIB e concentram as cinco maiores cidades do estado. Essa diferença nas Razões de Dependência apresentadas pelas Mesorregiões se deve, em parte, a maior demanda por mão de obra apresentada por essas Mesorregiões, consequentemente, maior concentração da população em idade ativa.

\section{CONSIDERAÇÕES FINAIS}

Como se pode perceber a transição demográfica se inicia com a queda da taxa de mortalidade da população sob análise, que aumenta a esperança de vida da mesma, e continua com a redução da taxa de natalidade, que promove a queda no tamanho das famílias, este acontecimento por sua vez gera uma alteração na estrutura etária geral da população, a qual é caracterizada pela redução da base da pirâmide populacional e o aumento de seu topo, fato facilmente visualizável nas pirâmides do Estado do Paraná.

Tanto que entre 1970 e 2010, a participação da população paranaense com idade entre 0 e 14 anos reduziu-se de $45,38 \%$ da população total do estado e para $22,89 \%$. E além disto, visualiza-se claramente o fato de que a participação da População em Idade Ativa (PIA) paranaense elevou-se de 52,26\%, em 1970, para 69,55\%, em 2010.

Outrossim a participação da população com idade acima de 65 anos também cresceu de $2,23 \%$ para $7,56 \%$. Este comportamento foi acompanhado da redução do peso relativo da população com faixa etária entre 0 e 14 anos e o aumento do peso da população entre 15 e 64 anos e acima de 65 anos, ocorrência que se fez presente em todas as Mesorregiões paranaenses entre 1991 e 2010.

Como foi verificado, a mudança na estrutura etária da população, resultante da transição demográfica, altera a Razão de Dependência (RD), que corresponde à 
soma da população de crianças/adolescentes e idosos dividida pela população em idade ativa.

No caso do Estado do Paraná, o que ser percebe é que em 1980, a RD era de $74,24 \%$. Isto significa que para cada 100 pessoas em idade produtiva existiam quase 75 pessoas "dependentes". Em 2010, a RD reduziu-se para aproximadamente 44 pessoas "dependentes" para cada 100 pessoas em idade ativa. A queda da RD também foi observada em todas as Mesorregiões Geográficas do Paraná entre 1991 e 2010.

Isto torna-se importante porque como já argumentado no artigo o conhecimento das mudanças na estrutura etária da população é fator fundamental para o aumento da eficácia das políticas públicas direcionadas para os segmentos específicos da estrutura etária da população, tais como educação, saúde, mercado de trabalho e previdência social.

Isto se torna evidente a partir do fato de que a população entre 0 e 14 anos continuará crescendo em termos absolutos. Entretanto, crescerá a taxas menores. Fato que reduzirá, por exemplo, a demanda por educação destas faixas etárias, o que permitirá a melhora da qualidade do ensino fundamental e médio. O mesmo ocorre com as políticas direcionadas para a saúde destinadas a crianças e jovens, como, por exemplo, campanhas de vacinação, que podem ampliar sua cobertura.

Ademais o aumento da longevidade ampliará o período de participação da população idosa nos programas de seguridade social e programas de transferência de renda, como aposentadoria rural. Isto afetará o sistema previdenciário brasileiro, pois um número crescente de beneficiários dependerá de uma quantidade menor de trabalhadores. Neste sentido, a informalidade pode comprometer a sustentação do sistema previdenciário. Isto torna necessária a elaboração de políticas públicas para reduzir a informalidade no mercado de trabalho.

Desta forma percebe-se de modo claro que no caso presente, o Dividendo Demográfico constitui-se uma "janela de oportunidade" para o crescimento econômico do Paraná bem como para o seu desenvolvimento, pois a maior participação da PIA possibilita o aumento da produção de bens e serviços. O Bônus, entretanto, é passageiro. Para que ele seja aproveitado são necessárias políticas públicas para, por exemplo, absorver esta PIA, de modo promover desenvolvimento econômico e o bem-estar da população; caso o não seja aproveitado, pode acarretar problemas sociais, como desemprego e aumento da desigualdade.

Assim, a transição demográfica, que ocorre tanto no Brasil quanto no Paraná e em suas Mesorregiões, deve ser aproveitada para reduzir a desigualdade e aumentar a mobilidade social, por meio, por exemplo, da ampliação e melhora na qualidade do ensino fundamental e médio. As políticas destinadas aos jovens devem ser prioridade para que eles não se tornem trabalhadores não contribuintes e não necessitem de transferências de renda no longo prazo, pois durante o período do bônus demográfico a força de trabalho crescerá mais rapidamente que a população dependente e com isso surgirá uma "janela de oportunidade" para direcionar mais recursos para o investimento no bem-estar das famílias e da economia.

Entretanto, as condições demográficas por si só não garantem o aproveitamento do bônus demográfico. É preciso assegurar a existência de políticas adequadas para viabilizar essa oportunidade. 


\section{REFERÊNCIAS}

ALVES, José Eustáquio Diniz. A transição demográfica e a janela de oportunidade. Artigo escrito em: 2008. Disponível em:

$<$ http://www.braudel.org.br/pesquisas/pdf/transicao_demografica.pdf>. Acesso em:

07/10/2013.

ALVES, José Eustáquio Diniz. A transição da fecundidade no Brasil entre 1960 e 2010. Artigo escrito em: 21/11/2011. Disponível em:

<http://www.ie.ufrj.br/aparte/pdfs/art_100_a_transicao_da_fecundidade_no_brasil_19 60_2010_21nov11.pdf>. Acesso em: 06/01/2013.

ALVES, José Eustáquio Diniz. Como medir o tempo de duração do Bônus Demográfico?. Disponível em:

$<$ http://fernandonogueiracosta.files.wordpress.com/2010/03/como-medir-o-tempo-dobonus-demografico.pdf>. Acesso em: 07/10/2013.

ALVES, José Eustáquio Diniz; CAVENAGHI, Suzana. Tendências demográficas, dos domicílios e das famílias no Brasil. Artigo escrito em: 24/08/2012. Disponível em:

$<$ http://www.ie.ufri.br/aparte/pdfs/tendencias demograficas e de familia 24ago12.p $\underline{\mathrm{df}}>$. Acesso em: 02/01/2013.

ALVES, José Eustáquio Diniz; BRUNO, Miguel A. P. População e crescimento econômico de longo prazo no Brasil: como aproveitar a janela de oportunidade demográfica?. Artigo escrito em: 2006. Disponível em:

<http://www.abep.nepo.unicamp.br/encontro2006/docspdf/ABEP2006 302.pdf>. Acesso em 24/07/2014.

AMARAL, Ernesto F. L. 2008. Transição demográfica e desenvolvimento econômico. Presentation at the course Brazilian Economy of Professor Afonso Henriques Borges Ferreira at Fundação João Pinheiro. Belo Horizonte, MG: FJP. November 27, 2008.

BRITO, Fausto; CARVALHO, José Alberto Magno de; BAENINGER, Rosana; TURRA, Cássio Maldonado; QUEIROZ, Bernardo Lanza. A transição demográfica e as políticas públicas no Brasil: crescimento demográfico, transição da estrutura etária e migrações internacionais. Artigo escrito em: Março de 2007. Disponível em: $<$ http://www.sae.gov.br/site/wp-content/uploads/07demografia1.pdf>. Acesso em: $11 / 01 / 2013$.

CARVALHO, José Alberto Magno de. Crescimento populacional e estrutura demográfica no Brasil. Artigo escrito em: Fevereiro de 2004. Disponível em: <http://www.cedeplar.ufmg.br/pesquisas/td/TD\%20227.pdf>. Acesso em: 08/01/2013.

CARVALHO, José Alberto Magno de; RODRIGUEZ-WONG, Laura L.. A transição da estrutura etária da população brasileira na primeira metade do século XXI. Cad.

Saúde Pública, Rio de Janeiro, v. 24, n. 3, p. 597-605, mar./2008. 
INSTITUTO BRASILEIRO DE GEOGRAFIA E ESTATÍSTICA (IBGE). Censos Demográficos. Disponível em:

Acesso em: 05/08/2013.

. Evolução e perspectivas da mortalidade infantil no Brasil. Artigo escrito em: 1999. Disponível em:

<http://www.ibge.gov.br/home/estatistica/populacao/evolucao_perspectivas_mortalid ade/evolucao_mortalidade.pdf>. Acesso em: 02/01/2013.

. Indicadores sociodemográficos e de saúde no Brasil 2009. Artigo escrito em: 2009. Disponível em:

<http://www.ibge.gov.br/home/estatistica/populacao/indic_sociosaude/2009/com_din. pdf>. Acesso em: 07/01/2013.

INSTITUTO PARANAENSE DE DESENVOLVIMENTO ECONÔMICO E SOCIAL (IPARDES). Mesorregiões geográficas do Estado do Paraná. Escrito em 2010. Disponível em: $<$ http://www.ipardes.gov.br/pdf/mapas/base fisica/mesorregioes geograficas base 2010.pdf>. Acesso em: 03/08/2013.

Acesso em: 07/10.2013.

Razão de dependência. Disponível em:<http://www.ipardes.gov.br/>.

NADALIN, Sergio Odilon. História e demografia: elementos para um diálogo.

Campinas: ABEP, 2004. Disponível em:

$<$ http://www.abep.nepo.unicamp.br/docs/outraspub/Demographicas1/demographicas 1 completo.pdf>. Acesso em: 04/01/2013.

RIPPEL, R. Migração e desenvolvimento econômico no Oeste do Estado do

Paraná: Uma análise de 1950 a 2000. Tese (Doutorado em Demografia). Instituto de Filosofia e Ciências Humanas, Universidade Estadual de Campinas. 2005

SILVA, Harley; MONTE-MÓR, Roberto L.. Transições demográficas, transição urbana, urbanização extensiva: um ensaio sobre diálogos possíveis. In: XVII Encontro Nacional de Estudos Populacionais, 2010, Caxambu. Disponível em: $<$ http://www.abep.nepo.unicamp.br/encontro2010/docs pdf/tema 3/abep2010 2530. pdf>. Acesso em: 04/01/2013.

VIGNA, Bruno Zanotto. A previdência social brasileira após a transição demográfica: simulações de propostas de reforma. In: XXXIV Encontro Nacional de Economia, 2006, Salvador. Disponível em:

<http://www.anpec.org.br/encontro2006/artigos/A06A033.pdf >. Acesso em: 04/01/2013. 